\title{
CORRECTION
}

\section{Correction to: Can we diagnose disk and facet degeneration in lumbar spine by acoustic analysis of spine sounds?}

\author{
Vugar Nabi ${ }^{1} \cdot$ Selim Ayhan ${ }^{2} \cdot$ Emre Acaroglu ${ }^{3} \cdot$ Mustafa Arda Ahi ${ }^{4}\left([) \cdot\right.$ Engin Çetin $^{7} \cdot$ Hakan Toreyin $^{5} \cdot$ \\ A. Enis Cetin 6
}

Published online: 10 November 2020

(c) Springer-Verlag London Ltd., part of Springer Nature 2020

\section{Correction to:}

\section{Signal, Image and Video Processing https://doi.org/10.1007/s11760-020-01776-3}

Unfortunately, the authors have missed to include the fifth author name (Engin Çetin) in the group.
The correct order of authors must read as follows:

Vugar Nabi, Selim Ayhan, Emre Acaroglu, Mustafa Arda Ahi, Engin Çetin, Hakan Toreyin, \& A. Enis Cetin.

Publisher's Note Springer Nature remains neutral with regard to jurisdictional claims in published maps and institutional affiliations.
The original article can be found online at https://doi.org/10.1007/s11 760-020-01776-3.

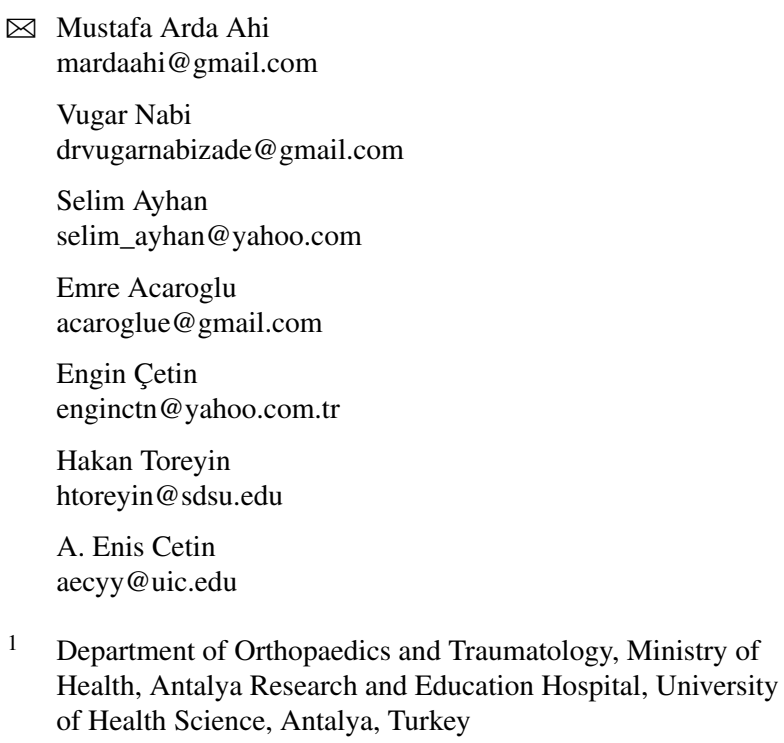

1 Department of Orthopaedics and Traumatology, Ministry of Health, Antalya Research and Education Hospital, University of Health Science, Antalya, Turkey

2 Department of Neurosurgery, Başkent University Hospital, Ankara, Turkey

3 Ankara Spine Center, İran Caddesi 45/2 Kavaklıdere, Ankara, Turkey

4 BAE Systems, Marconi Way, Chatham, Rochester, Kent ME1 2XX, UK

5 Department of Electrical and Computer Engineering, San Diego State University, San Diego, CA, USA

6 Department of Electrical and Computer Engineering, University of Illinois at Chicago, Chicago, IL 60640, USA

7 Gaziosmanpasa Training and Research Hospital, Istanbul, Turkey 